\title{
Como copiar e executar tarefas com um arquivo .cdb (ADAMS/Car) em seu computador
}

ATENÇÃO: o leitor tem acesso a duas pastas .cdb das suspensões independentes: Macpherson e Duplo "A". Cada uma dessas pastas deve ser aberta individualmente, conforme indicado nos passos especificados abaixo.

\section{Primeiro passo}

Faça o download da pasta compactada referente aos tutoriais das Suspensões Macpherson e Duplo "A" no local desejado em seu computador. Por exemplo, no diretório C:I, crie uma pasta de nome "Suspensão_Macpherson" e outra "Suspensão_duploA". Copie para dentro dessas pastas o respectivo arquivo compactado.

\section{Segundo passo}

Descompacte os arquivos nas referidas pastas tendo o cuidado de manter os mesmos nomes, quais sejam: 
- Tutorial_macpherson.cdb (caso vá trabalhar com a suspensão Macpherson) ou

- Tutorial_duploa.cdb (caso vá trabalhar com a suspensão Duplo “A”)

Obs.: o botão direito do mouse permite que clicando sobre o arquivo compactado e selecionando a opção: "Extrair para Tutorial_macpherson.cdb" ou "Extrair para Tutorial_duploa.cdb", os arquivos sejam copiados nas pastas criadas anteriormente.

\section{Terceiro passo}

Inicie o ADAMS/Car clicando no ícone referente a ele e, em seguida, escolha, conforme tela abaixo a opção "Standard Interface".

Welcome to Adams/Car...

- Standard Interface

C Template Builder

\section{OK}

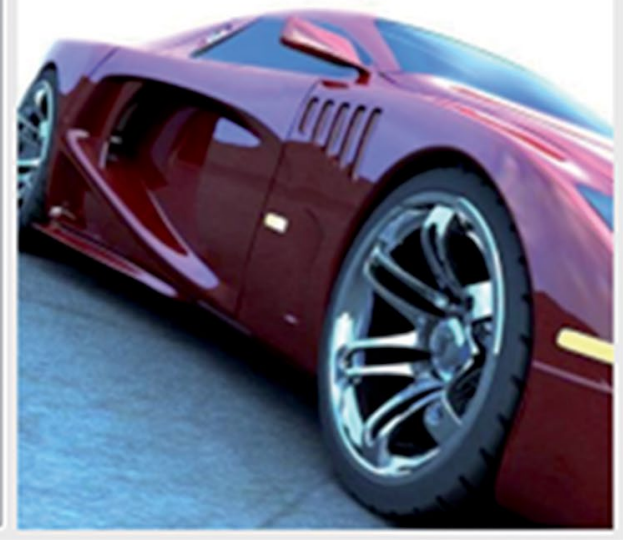

\section{Quarto passo}

Em seguida, selecione a opção File $\rightarrow$ Select Directory e navegue de forma a indicar o local onde a pasta .cdb foi armazenada em seu computador (selecione o último nível desta pasta). Por exemplo:

C:ISuspensao_Macpherson\Tutorial_macpherson.cdb\Tutorial_macpherson.cdb ou

C:ISuspensao_duploa $\backslash$ Tutorial_duploa.cdb\Tutorial_duploa.cdb 


\section{Quinto passo}

Por fim, vá ao menu principal e selecione a opção Tools $\rightarrow$ Database Management $\rightarrow$ Add to Session para carregar a pasta .cdb na sessão aberta do ADAMS/Car.

Neste caso, deve-se informar o Database Alias, que é o próprio nome da pasta .cdb (Tutorial_duploa ou Tutorial_macpherson) e o Database Path, que indica o local onde a mesma se encontra (C:Suspensao_Macpherson\Tutorial_macpherson.

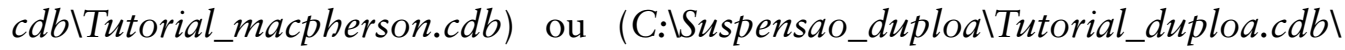
Tutorial_duploa.cdb).

\section{Sexto passo}

O subsistema existente na pasta descompactada já pode ser aberto. Para isto vá em File $\rightarrow$ Open $\rightarrow$ Subsystem . Na caixa de diálogo Open Subsystem, clique com o botão direito do mouse na caixa de texto e em seguida clique em Browse. Duplo clique na pasta subsystems.tbl e em sequência selecione o arquivo tutorial_macpherson.sub ou tutorial_duploa.sub. Clique em $O K$ em ambas as janelas. Clique em Close para fechar a janela que se abrirá sobre a área de trabalho. Pronto, seu modelo já está pronto para ser trabalhado. 
